\title{
Causes and frequency of blindness in patients with intraocular inflammatory disease
}

\author{
Aniki Rothova, Maria S A Suttorp-van Schulten, W Frits Treffers, Aize Kijlstra
}

\begin{abstract}
Aims/Background-Uveitis, an intraocular inflammatory disease, is a significant cause of visual impairment. It is not known how many patients with uveitis will retain visual acuity and how many develop visual impairment or even blindness. The aim of this study was to assess the frequency of blindness in patients with uveitis and, more specifically, to identify the clinical profile of patients at risk for visual loss.

Methods-A cross sectional and retrospective study of 582 patients with uveitis who visited the ophthalmology departments of two university hospitals in the Netherlands was performed.
\end{abstract}

Results-Within the group of 582 patients, $203(35 \%)$ exhibited blindness or visual impairment; bilateral legal blindness developed in $22(4 \%)$ patients, $26(4 \cdot 5 \%)$ had one blind eye with visual impairment of the other, and nine (1.5\%) had bilateral visual impairment. Unilateral blindness developed in $82(14 \%)$ patients, whereas 64 (11\%) exhibited unilateral visual impairment. The most important cause of both blindness and visual impairment was cystoid macular oedema $(29 \%$ and $41 \%$, respectively). Complications of uveitis were encountered in more than half of the patients and $23 \%$ underwent one or more surgical procedures. When the patients were subdivided according to anatomical site, those with panuveitis had the worst visual prognosis. The systemic diseases associated with a poor visual prognosis were juvenile chronic arthritis and sarcoidosis. Ocular toxoplasmosis was the most frequent cause of unilateral visual loss.

Conclusions-Cystoid macular oedema is the most frequent complication of uveitis and its occurrence plays a decisive role in the visual outcome of this disease.

(Br F Ophthalmol 1996; 80: 332-336)

Uveitis, an intraocular inflammatory disease, is a major cause of severe visual impairment. The number of patients blind as a result of uveitis is unknown; it has been estimated that uveitis accounts for $10 \%$ to $15 \%$ of all cases of total blindness in the United States. ${ }^{1}$ The decrease in visual acuity may be attributable to cataract formation, secondary glaucoma, vitreous opacities, cystoid macular oedema, retinal scars, and other causes. ${ }^{2}$ The prevalence of uveitis reported in 1984 was 38 per 100000 in a general population: the annual incidence was approximately 17 per 100000 with maximum incidence in the 25 to 44 year age group. ${ }^{3}$ In surveys of the causes of blindness uveitis is usually not included and is probably underestimated. The sequelae of uveitis are considered to be the direct cause of visual loss (for example, cataract, glaucoma) while the primary cause of the decrease in visual acuity (uveitis) is not mentioned. In a recent hospital based survey of blindness in West Africa, in which these sequelae were correctly attributed to uveitis, this disease was the second leading cause of blindness; this indicates how large the proportion of patients with uveitis is among the blind. ${ }^{4}$ In the Netherlands (1975-7), in a hospital based study, uveitis caused $6 \%$ of all blindness and ranked fifth after diabetic retinopathy, age-related macular degeneration, tapetoretinal dystrophy, and glaucoma. ${ }^{5}$ In the 1993 annual report of Research to Prevent Blindness, an estimated 2300000 Americans suffer visual impairment because of this major sight robbing disease. ${ }^{6}$

It is not known how many patients with uveitis retain useful visual acuity and how many develop a visual handicap or even blindness. We therefore performed a retrospective study of 582 patients with uveitis of various origins to assess the frequency of blindness and visual handicap in that population and, more specifically, to identify the clinical profile of uveitis patients at risk for visual impairment.

\section{Subjects and methods}

The study included 280 consecutive patients with uveitis who visited the ophthalmology department of the University Hospital in Utrecht during 1993 and were followed for more than 1 year and 302 patients with uveitis followed for more than 1 year and chosen at random (numeric code) from the data bank of patients from the Academic Medical Centre in Amsterdam. Both institutions combine secondary and tertiary ophthalmological care; patients are referred by ophthalmologists from a large area and also by general practitioners from a smaller local area. When the patients from the two study locations were compared, their general characteristics such as male to female ratio, unilateral or bilateral involvement, site of the inflammation, tertiary referral, and duration of follow up did not differ significantly $(p>0.05)$. The majority of patients were referred by an ophthalmologist $(358 ; 61 \%) ; 127$ $(22 \%)$ were referred by their primary health care physician and occasional patients were referred by the emergency department or other (nonophthalmological) specialists within the hospital itself. The mean follow up period was $4 \cdot 3$ years. 
Table 1 Visual loss in uveitis

\begin{tabular}{lclll}
\hline & $\begin{array}{l}\text { Bilateral legal } \\
\text { blindness } \\
n(\%)\end{array}$ & $\begin{array}{l}\text { Bilateral visual } \\
\text { impairment } \\
n(\%)\end{array}$ & $\begin{array}{l}\text { Unilateral legal } \\
\text { blindness } \\
n(\%)\end{array}$ & $\begin{array}{l}\text { Unilateral visual } \\
\text { impairment } \\
n(\%)\end{array}$ \\
\hline Anterior uveitis $(\mathrm{n}=246)$ & $4(2)$ & $7(3)$ & $22(9)$ & $13(5)$ \\
Intermediate uveitis $(\mathrm{n}=78)$ & $0(0)$ & $4(5)$ & $8(10)$ & $10(13)$ \\
Posterior uveitis $(\mathrm{n}=129)$ & $8(6)$ & $3(2)$ & $28(22)$ & $20(16)$ \\
Panuveitis $(\mathrm{n}=107)$ & $10(9)$ & $20(19)$ & $21(19)$ & $19(12)$ \\
Scleritis $(\mathrm{n}=22)$ & $0(0)$ & $1(5)$ & $3(14)$ & $2(9)$ \\
Total $(\mathrm{n}=582)$ & $22(4)$ & $35(6)^{\star}$ & $82(14)^{\star}$ & $64(11)$ \\
\hline
\end{tabular}

*There were 26 patients with a combination of legal blindness in one eye and visual impairment of the other eye; they are included in the group 'bilateral visual impairment' and not the group

'unilateral legal blindness'. (equal to or better than $20 / 400$ but less than 20/200) and blindness (from no light perception to 20/400). ${ }^{14}$ The criterion for visual impairment was a best corrected visual acuity equal to or less than 0.3 for the eye with better vision. To determine the visual loss, the final visual acuity was used and not the worst visual acuity at any visit. In patients with more than one complication, the cause of visual loss was attributed to the first complication which caused the final blindness or visual impairment (for example, first, toxoplasmic macular lesion followed by retinal detachment). Visual loss due to other causes which were not related to uveitis (for example, amblyopia) was not included in the final evaluation. However, the complications from the treatment for uveitis (for example, steroid induced cataract) were included.

Glaucoma was considered in the eyes with the combination of elevated intraocular pressure and visual field defects and not in cases with ocular hypertension only. The visual field loss from glaucoma resulting in less than 10 degree field was considered one of the criteria of legal blindness.

Cystoid macular oedema was defined by both clinical and angiographic criteria. Angiographic evidence was required in all cases where the cause of legal blindness of visual impairment was attributed to macular oedema.

We used the $\chi^{2}$ test for statistical analysis. A $p$ value of less than 0.01 was considered significant.

lacrimal gland biopsies, Mantoux test, serological tests for Toxoplasma and Borrelia, and aqueous or vitreous humour analysis for evidence of intraocular synthesis of specific antiparasitic and antiviral antibodies. Since the serological tests for Toxoplasma are positive for a considerable percentage of the general population and therefore are not indicative of active ocular involvement, ${ }^{11}$ the diagnosis of presumed ocular toxoplasmosis was based on the clinical observation of unilateral focal necrotising retinitis, sometimes associated with typical old pigmented scars. The diagnosis of sarcoidosis was always confirmed by histological examination of biopsy specimens. The diagnosis of ankylosing spondylitis was based on the criteria described by Bennet and Burch. ${ }^{12}$ All other systemic diseases were diagnosed according to current diagnostic criteria; the patients were also examined by the respective specialists. AIDS patients were not included in this study; because the tests for anti-human immunodeficiency virus (HIV) were not routinely performed, the number of eventually HIV infected patients without AIDS is not known.

The following data were recorded: sex and age of the patients, age at the onset of uveitis, referring physician, anatomical site and aetiological agent of uveitis, eventual associations with systemic diseases, all complications of uveitis and the subsequent treatment, and maximum visual acuity at the end of follow up.

Legal blindness was defined as a best corrected visual acuity of less than $0 \cdot 1$ for the better eye. ${ }^{13}$ This corresponds to the standard WHO definitions of severe visual impairment

\section{Results}

Within the group of 582 patients, 203 (35\%) suffered from significant visual loss: bilateral legal blindness developed in $22(4 \%), 26$ $(4.5 \%)$ had one blind eye with visual impairment of the other, and nine $(1.5 \%)$ had bilateral visual impairment (Table 1). Unilateral visual loss occurred in $146(25 \%)$, blindness in $82(14 \%)$, and visual impairment in $64(11 \%)$ patients.

In this patient series, anterior uveitis was the predominant anatomical diagnosis (246 cases; $42 \%) ; 129(22 \%)$ presented with posterior uveitis, $107(19 \%)$ with panuveitis, $78(13 \%)$ with intermediate uveitis, and $22(4 \%)$ with scleritis. When the patients were subdivided according to anatomical site, those with panuveitis had the worst visual prognosis; $9 \%$ of patients with panuveitis became legally blind and $19 \%$ suffered bilateral visual impairment (Table 1). Cystoid macular oedema developed in $22(9 \%)$ patients with anterior uveitis, 32 $(41 \%)$ with intermediate uveitis, $36(28 \%)$ with posterior uveitis, 57 (53\%) with panuveitis, and three $(14 \%)$ with scleritis.

Cystoid macular oedema was the most frequent cause of both irreversible blindness and visual impairment: $33 / 152(29 \%)$ of affected blind eyes and $46 / 113(41 \%)$ of visually impaired eyes. In the majority of cases bilateral visual loss was caused by a combination of various complications, so that a different cause of the visual handicap could be determined for each eye. The most important cause of visual 
Table 2 Complications of uveitis ( $n=582$ )

\begin{tabular}{lrc}
\hline & \multicolumn{3}{c}{ Patients } \\
\cline { 2 - 3 } & $n$ & $\%$ \\
\hline Cystoid macular oedema & 150 & 26 \\
Cataract & 15 & 19 \\
Glaucoma & 66 & 11 \\
Retinal vascular abnormalities & 64 & 11 \\
Macular lesion & 30 & 5 \\
Retinal detachment & 26 & $4 \cdot 5$ \\
Corneal opacities & 24 & 4 \\
Phthisis & 14 & $2 \cdot 4$ \\
Optic nerve atrophy & 13 & 2 \\
Miscellaneous & 42 & 7 \\
Total of patients with one or more complications & $322^{\star}$ & 55 \\
\end{tabular}

*There were many patients with more than one complication: therefore the total number of patients is less than the total number of complications.

Table 3 Surgery in uveitis

\begin{tabular}{llll}
\hline & & \multicolumn{2}{c}{ With surgery } \\
\cline { 3 - 4 } Follow up & $n$ & $n$ & $\%$ \\
\hline$\geqslant 1$ Year & 582 & 136 & 23 \\
>1 Year & 430 & 125 & 29 \\
>2 Years & 276 & 103 & 37 \\
>3 Years & 219 & 89 & 41 \\
\hline
\end{tabular}

loss per eye was cystoid macular oedema followed by corneal opacities and macular inflammatory lesions. Causes of unilateral blindness and visual impairment, which were more consistent, included cystoid macular oedema, macular inflammatory lesions, retinal vascular abnormalities, and retinal detachment. Complications of uveitis were encountered in more than half of the patients; the distribution is given in Table 2 .

In total, $136(23 \%)$ patients required one or more intraocular surgical procedures. The percentage of those requiring surgery increased with the duration of follow up (Table 3). The most frequent surgical procedures were cataract extractions $(n=76)$, vitrectomy $(n=38)$, and surgery for glaucoma $(n=25)$ and retinal detachment $(n=16)$. Laser treatment (retina, iris, after cataract) was performed in 37 cases. Since the patients who developed cataract underwent extraction, this complication was not encountered as a cause of blindness, but ranked second as a cause of (temporary: waiting for surgery) visual impairment. Cystoid macular oedema was present in $32 / 76(42 \%)$ patients after cataract surgery and

Table 4 Visual loss in uveitis

\begin{tabular}{lcccc}
\hline & $\begin{array}{l}\text { Bilateral } \\
\text { legal } \\
\text { blindness }\end{array}$ & $\begin{array}{l}\text { Bilateral } \\
\text { visual } \\
\text { impairment }\end{array}$ & $\begin{array}{l}\text { Unilateral } \\
\text { legal } \\
\text { blindness }\end{array}$ & $\begin{array}{l}\text { Unilateral } \\
\text { visual } \\
\text { impairment }\end{array}$ \\
\hline HLA B27 positive acute anterior uveitis $(\mathrm{n}=63)$ & 0 & 0 & 3 & 3 \\
Toxoplasmosis $(\mathrm{n}=60)$ & 0 & 0 & 12 & 9 \\
Sarcoidosis $(\mathrm{n}=56)$ & 1 & 7 & 1 & 5 \\
Fuchs' cyclitis $(\mathrm{n}=31)$ & 0 & 2 & 3 & 3 \\
Multifocal choroiditis $(\mathrm{n}=24)$ & 1 & 2 & 6 & 4 \\
Juvenile chronic arthritis $(\mathrm{n}=8)$ & 2 & 3 & 1 & 0 \\
Acute retinal necrosis $(\mathrm{n}=6)$ & 1 & 1 & 4 & 0 \\
Birdshot retinochoroidopathy $(\mathrm{n}=5)$ & 1 & 1 & 1 & 1 \\
Behçet disease $(\mathrm{n}=5)$ & 0 & 0 & 3 & 0 \\
Serpiginous retinochoroidopathy $(\mathrm{n}=5)$ & 2 & 0 & 1 & 0 \\
Miscellaneous $(\mathrm{n}=119)$ & 3 & 6 & 19 & 13 \\
Undetermined $(\mathrm{n}=200)$ & 11 & 13 & 28 & 26 \\
Total $(\mathrm{n}=582)$ & 22 & 35 & 82 & 64 \\
\hline
\end{tabular}

*This group included 26 patients with a combination of legal blindness in one eye and visual impairment of the other (three with sarcoidosis, three with juvenile chronic arthritis, two with Fuchs' cyclitis, one with acute retinal necrosis, and one with multifocal chorioretinitis, 16 with miscellaneous and undetermined conditions).
$15 / 39(39 \%)$ patients with a cataract still in situ. Glaucoma ranked third among the complications of uveitis; 25 of the $66(38 \%)$ patients with uveitic glaucoma underwent surgery.

The most frequent systemic disorders associated with uveitis were sarcoidosis $(n=56$; $10 \%)$ and ankylosing spondylitis $(n=20 ; 3.4 \%$; an additional 43 patients had HLA B27 associated acute anterior uveitis without ankylosing spondylitis); the most common ocular disease was ocular toxoplasmosis $(n=60 ; 10 \%$; Table 4). The frequency of bilateral blindness and visual impairment among patients with uveitis of unknown aetiology did not differ significantly from that found for uveitis of known aetiology (blindness $5.5 \%$ versus $2.9 \%, p=0 \cdot 1$; visual impairment $7 \cdot 5 \%$ versus $5 \cdot 2 \%, p=0 \cdot 3$; Table 4).

Bilateral visual blindness or impairment occurred in uveitis of unknown origin in $42 \%$ $(24 / 57)$ and $14 \%(8 / 57)$ of bilaterally blind patients had uveitis associated with (histologically confirmed) sarcoidosis (Tables 1 and 4). Uveitis in juvenile chronic arthritis had the worst visual prognosis; five out of eight patients suffered bilateral visual impairment or blindness. Of the 63 patients with HLA B27 associated acute anterior uveitis, none exhibited bilateral visual loss; there were three cases of unilateral blindness and three of unilateral impairment. Ocular toxoplasmosis was the most frequent cause of both unilateral legal blindness and unilateral visual impairment; this was attributed to the site of the retinal inflammatory lesion in the macula. None of the 60 patients with ocular toxoplasmosis experienced bilateral loss of vision. None of five patients with Behçet's disease was bilaterally blind; however, three developed unilateral blindness.

\section{Discussion}

Within the group of 582 patients, 203 (35\%) developed blind or visually impaired eyes. Bilateral loss of visual acuity developed in $10 \%$ and unilateral loss of vision occurred in an additional $25 \%$ of all patients with uveitis. The principal mechanism of visual loss in uveitis was cystoid macular oedema.

In the Netherlands, the patient is referred for either diagnostic or therapeutic help in the event of recurrent, chronic, or very severe acute uveitis. Acute cases which respond favourably to therapy are usually not referred. Although the results from two centres included did not differ significantly, the variability in timing of referral and the treatment given may have influenced the overall outcome and the findings should be interpreted with caution. The retrospective character of this study did not allow the clinically relevant evaluation of the relation between the therapy data and visual prognosis.

Uveitis may be caused directly by various infectious agents; in the majority of such cases specific antimicrobial therapy is available. Uveitis may also be associated with diverse, usually idiopathic, systemic diseases (for 
example, Behçet's disease); the treatment strategies for these diseases are continuously being developed. ${ }^{15}$ The identification of a specific ocular disease (usually of unknown aetiology and without an underlying systemic disease - for example, Fuchs' heterochromic uveitis, pars planitis) is important for the visual prognosis since information on clinical course, complications, and treatment regimens is then available. The surprising finding of the similarity in visual prognosis for patients with uveitis of established and undetermined origin is not easy to understand and certainly needs further study and evaluation.

Although cataract and glaucoma frequently complicated the course of uveitis $(19 \%$ and $11 \%$, respectively), their importance as a cause of the loss of optimal visual acuity remained limited. Cataract surgery in uveitic eyes may give rise to or exacerbate cystoid macular oedema. ${ }^{16}$ In this study, the frequency of cystoid macular oedema did not differ between patients who did or did not undergo cataract surgery. The design of our study, however, did not allow evaluation of the impact of cataract surgery on the increase in pre-existing macular oedema.

Of the systemic diseases, the most frequent cause of blindness was uveitis associated with sarcoidosis, especially in those suffering from panuveitis. The occurrence of blindness in at least one eye in $10 \%$ of the patients with sarcoidosis, as reported in an earlier publication, is supported by our results. ${ }^{17} 18$ The most frequent cause of unilateral loss of vision was ocular toxoplasmosis. There were no cases of bilateral blindness or visual impairment among the 60 patients with this disease. Studies on the visual outcome of ocular toxoplasmosis in large patient populations are not available and, therefore, the absence of bilateral visual loss in our patients cannot be compared with the results of other studies. ${ }^{19-21}$ Information on the long term prognosis of ocular toxoplasmosis (especially the congenital type of the disease) is urgently needed, since preventive measures for congenital toxoplasmosis are vigorously recommended. ${ }^{22} 23$ HLA B27 associated uveitis was reported to have a favourable visual outcome despite the occurrence of posterior segment complications; none of our 63 patients suffered bilateral visual loss. 2425 The comparison of our data on the less frequent types of uveitis with previously published reports on one disease entity is very difficult. The poor visual prognosis for acute retinal necrosis, juvenile chronic arthritis, and serpiginous chorioretinopathy noted even for the small numbers of patients in our study was known from previous publications. ${ }^{26-29}$ All patients with acute retinal necrosis $(n=6)$ developed visual loss (Table 4). Four of our five patients with birdshot chorioretinopathy became blind or impaired. The long term visual prognosis for birdshot retinochoroidopathy is not yet entirely clear: the disease has been reported to stabilise after the initial active stage while other series have demonstrated that $40 \%$ of the patients experienced a loss of useful vision in one or both eyes. ${ }^{30-32}$ There were no cases of bilateral blindness among five patients with Behçet's disease (mean follow up of 5 years). Behçet's disease has repeatedly been reported to have a poor visual prognosis although it seems that aggressive therapeutic management improves the long term visual outcome. ${ }^{33-35}$ The administration of aggressive cyclosporin A therapy in our cases may have improved our findings; however, it should also be noted that the number of patients was very small and our criteria for loss of visual acuity very strict.

Intermediate uveitis was complicated by cystoid macular oedema in $41 \%$ of the cases, which is in accordance with previous reports. ${ }^{36} 37$ When fluorescein angiography was performed repeatedly, the incidence of cystoid macular oedema in intermediate uveitis became even higher $(65-79 \%) .{ }^{38} 39$ Nevertheless the impact of cystoid macular oedema on visual acuity remained limited and the visual prognosis for cystoid macular oedema in intermediate uveitis was much better than that for cystoid macular oedema and panuveitis (Table 1).

We conclude that cystoid macular oedema was the most frequent complication among patients with uveitis and its occurrence played a decisive role in the visual outcome. The best treatment for uveitic macular oedema has yet to be identified. ${ }^{40}$ The timing of eventual treatment of macular oedema in uveitis patients is difficult, because the loss of visual acuity is gradual and therapy may induce many systemic and ocular complications. Therefore, treatment is usually not initiated until late in the disease process but then the reversible stage of the disease may already have passed. ${ }^{41}$ The causes of blindness in the western World are probably changing as a result of recent advances in diagnosis and therapy of ocular and systemic diseases, epidemiological changes, and other factors. As a consequence there may be a growing impact of uveitis on blindness, especially in the younger age groups. Recent surveys of the causes of blindness which focus not only on the ocular features but also on the underlying primary conditions, such as uveitis, are needed.

1 Nussenblatt RB. The natural history of uveitis. Int Ophthalmol 1990; 14: 303-8.

2 Forrester JV. Uveitis: pathogenesis. Lancet 1991; 338: 1498-501.

3 Vadot E, Barth E, Billet P. Epidemiology of uveitis - preliminary results of a prospective study in Savoy. In: Saar KM, ed. Uveitis update. Amsterdam: Elsevier, 1984: 13-6.

4 Ronday MJH, Stilma JS, Barbe RF, Kijlstra A, Rothova A. Blindness from uveitis in a hospital population in Sierra Blindness from uveitis in a hospital populat
Leone. Br $\mathcal{O}$ Ophthalmol 1994; 78: 690-3.

5 Doesschate ten J. Causes of blindness in the Netherlands. Doc Ophthalmol 1982; 52: 279-85.

6 Research to Prevent Blindness. Annual report 1993. 598 Madison Avenue, New York, 1993: 4.

7 Bloch-Michel E, Nussenblatt RB. International uveitis study group recommendations for the evaluation of intraocular inflammatory disease. Am $\mathcal{F}$ Ophthalmol 1987 103: 234-6.

8 Nussenblatt RB, Palestine AG. Scleritis. In: Uveitis. Fundamentals and clinical practice. Chicago: Year Book Medical Publishers, 1989: 239-41.

9 Sainz de la Maza M, Jabbur NS, Foster CS. Severity of scleritis and episcleritis. Ophthalmology 1994; 101: 389-96. 10 Rothova A, Buitenhuis HJ, Meenken C, Brinkman CJJ, Linssen A, Alberts C, et al. Uveitis and systemic disease. Br 7 Ophthalmol 1992; 76: 137-41.

11 Rothova A, van Knapen F, Baarsma GS, Kruit PJ, Loewer-

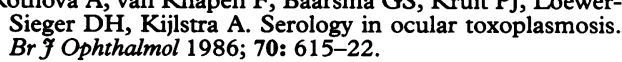


12 Bennet PH, Burch TA. New York symposium on population studies in the rheumatic diseases. New diagnostic criteria. Bull Rheum Dis 1967; 17: 453-8.

13 Kraut JA, McCabe CP. The problem of low vision. Definition and common problems. In: Albert DM Jakobiec FA, eds. Principles and practice of ophthalmology. Philadelphia: W B Saunders, 1994; 5: 3664-6.

14 McGavin M. Reaching for high standards of eye care. Community Eye Health 1993; 6: 1-2.

15 Lightman S. Uveitis: management. Lancet 1991; 338 1501-4.

16 Barton K, Hall AJH, Rosen PH, Cooling RJ, Lightman S. Systemic steroid prophylaxis for cataract surgery in patients with posterior uveitis. Ocular Immunology and Inflammation 1994; 2: 207-16.

17 Rothova A, Alberts C, Glasius E, Kijlstra A, Buitenhuis HJ Breebaart AC. Risk factors for ocular sarcoidosis. Doc Breebaart AC. Risk factors
Ophthalmol 1989; 72: 287-96.

18 Foster CS. Ocular manifestations of sarcoidosis preceding systemic manifestations. In: Grassi C, Rizatto G, Pozzi E, eds. Sarcoidosis and other granulomatous disorders. Amsterdam: Exerpta Medica, 1988: 177-81.

19 Loewer-Sieger DH, Rothova A, Koppe JG, Kijlstra A Congenital toxoplasmosis: a prospective study based on 1821 pregnant women. In: Saari KM, ed. Uveitis update. Amsterdam: Elsevier, 1984: 203-7.

20 Wilson CB, Remington JS, Stagno S, Reynold DW. Development of adverse sequelae in children born with subDevelopment of adverse sequelae in children born with sub-
clinical toxoplasma infection. Pediatrics $1980 ; 66: 767-74$.

21 McAuley J, Boyer KM, Patel D, Mets M, Swisher C, Roizen $\mathrm{N}$, et al. Early and longitudinal evaluations of treated infants and children and untreated historical patients with congenital toxoplasmosis: the Chicago collaborative treatment trial. Clin Infect Dis 1994; 18: 38-72.

22 McCabe R, Remington JS. Toxoplasmosis: the time has come. N Engl f Med 1988; 318: 313-5.

23 Foulon W, Naessens A, Derde MP. Evaluation of the possibilities for preventing congenital toxoplasmosis. $A m$ Sibilities for preventing congal 1994 ; 11 : $57-62$.

24 Rothova A, Veenendaal WG van, Linssen A, Glasius E, Kijlstra A, Jong PTVM de. Clinical features of acute anterior uveitis. Am $\mathcal{f}$ Ophthalmol 1987; 103: 137-45.

25 Rodriguez A, Akova YA, Pedroza-Seres M, Foster CS Posterior segment ocular manifestations in patients with HLA-B27 associated uveitis. Ophthalmology 1994; 101 1267-74.
26 Boer de JH, Luyendijk L, Rothova A, Baarsma GS, Jong de PTVM, Bollemeijer JG, et al. Detection of intraocular antibody production to herpesviruses in acute retinal necrosis syndrome. Am ₹ Ophthalmol 1994; 117: 201-10.

27 Wolf MD, Lichter PR, Ragsdale CG. Prognostic factors in the uveitis of juvenile rheumatoid arthritis. Ophthalmology 1987; 94: 1242-8.

28 Weiss H, Annesley WH Jr, Shields JA, Tomer T, Christopherson $\mathrm{K}$. The clinical course of serpiginous choroidopathy. Am f Ophthalmol 1979; 87: 133-42.

29 Laatikainen L, Erkkila $\mathrm{H}$. A follow-up study on serpiginou choroiditis. Acta Ophthalmol (Copenh) 1981; 59: 707-18.

30 Nussenblatt RB, Palestine AG. Birdshot retinochoroidopathy. In: Uveitis. Fundamentals and clinical practice. Chicago: Year Book Medical Publishers, 1989: 248-56.

31 Ryan SJ, Maumenee AE. Birdshot retinochoroidopathy. Am f Ophthalmol 1980; 89: 31-45.

32 Priem HA, Oosterhuis JA. Birdshot chorioretinopathy: clinical characteristics and evolution. $\mathrm{Br} \mathcal{F}$ Ophthalmo 1988; 72: 646-59.

33 Mamo JG. The rate of visual loss in Behçet's disease. Arch Ophthalmol 1970; 84: 451-2.

34 Cochereau-Massin I, Wechsler B, Le Hoang P, Le Th Huong Du, Girard B, Rousselie F, et al. Prognostic oculaire de la maladie de Behçet. F Fr Ophtalmol 1992; 15: 343-47.

35 Towler HMA, Lightman S. Visual prognosis is Behcet's disease. Ocular Immunology and Inflammation 1993; 1 disease.

36 Hikichi T, Trempe CL. Role of the vitreous in the prog-nosis of peripheral uveitis. Am $\mathcal{F}$ Ophthalmol 1993; 116: 401-5. 37 Malinowski SM, Folk JC, Pulido JS. Pars planitis. Curr Opin Ophthalmol 1994; 5: 72-82

38 Pruett RC, Brockhurst RJ, Letts NF. Fluorescein angiography of peripheral uveitis. Am f Ophthalmol 1974; 77 448-53.

39 Chester GH, Blach RK, Cleary PE. Inflammation in the region of the vitreous base. Pars planitis. Trans Ophthalmol region of the vitreous base.

40 Dick AD. The treatment of chronic uveitic macular oedema. Is immunosuppression enough? $\mathrm{Br} \mathcal{F}$ Ophthalmo 1994; 78: $1-2$

41 Heiligenhaus A, Bornfeld N, Foerster $\mathrm{MH}$, Wessing A Long term results of pars plana vitrectomy in the management of complicated uveitis. Br $\mathcal{F}$ Ophthalmol 1994; 78: 549-54. 